\title{
POKOJE WYCISZEŃ - WSPÓŁCZESNE TENDENCJE PROJEKTOWANIA
}

\author{
Bartłomiej Kwiatkowski \\ Politechnika Lubelska, Wydział Budownictwa i Architektury, Katedra Architektury, \\ Urbanistyki i Planowania Przestrzennego Politechniki Lubelskiej.
}

\begin{abstract}
Streszczenie. W ciągu ostatniej dekady znacznie wzrosła ilość osób ze zdiagnozowanym „spektrum zaburzeń autystycznych". Na podstawie szacunkowych danych można określić, iż w Polsce jest ponad. 30 tys. osób chorych na autyzm, w związku z powyższym liczba osób, których dotyczy ten problem wynosi ponad 100 tys. w Polsce.

Rosnące zapotrzebowanie na obiekty i przestrzenie publiczne dostosowane dla potrzeb tej grupy osób wymaga usystematyzowania wiedzy zakresie projektowania architektonicznego uwzględniającego wymagania osób ze spectrum zabużeń autystycznych. W artykule przedstawiono podstawowe zasady kształtowania tzw. Pokoi wyciszeń" coraz częściej lokalizowanych w obiektach użyteczności publicznej.
\end{abstract}

Słowa kluczowe: autyzm, psychologia środowiskowa, projektowanie, budynki użyteczności publicznej

W roku 2014 przeprowadzono na obszarze Polski badania w ramach projektu Projekt „Od wykluczenia do integracji - w obronie podstawowych praw osób z autyzmem” realizowany przy wsparciu Szwajcarii w ramach szwajcarskiego programu współpracy z nowymi krajami członkowskimi Unii Europejskiej, w okresie od 1.01.2013 r. do 30.09.2014 r. ${ }^{1}$.

Wyniki badań oparto na danych przesłanych przez:

45\% urzędów samorządów gmin/dzielnic (593 z 1310),

$52 \%$ urzędów samorządów powiatów (92 z 176),

$100 \%$ urzędów samorządów województw ( 7 z 7),

$54 \%$ OPS (703 z 1310),

$57 \%$ PCPR (82 z 176),

$8 \%$ placówek (19 na 242$)^{2}$.

W wyniku badań stwierdzono iż ani gminy, ani powiaty, ani organizacje pozarządowe nie posiadają wiedzy dotyczącej ilości osób ze spectrum zaburzeń autystycznych na obszarach ich podległym. Jednocześnie dane podawane przez różne podmioty z określonego obszaru są bardzo zróżnicowane. Do dnia dzisiejszego nie powołano w Polsce żadnej instytucji, której zadaniem byłoby zbieranie takich danych, a żadna $\mathrm{z}$ działających już instytucji nie podejmuje działań na rzecz ich zebrania. Jedną z metod zbierania $w$ miarę obiektywnych danych na temat osób $\mathrm{z}$ autyzmem są wnioski o pomoc składane na piśmie przez rodziny osób z autyzmem, jednak rodzice rzadko składają takie wnioski, wiedząc że samorządy i tak nie mają oferty dla ich dzieci. Jedynie 9\% gmin prowadzi statystyki lub szacunki odnośnie liczby dorosłych osób $\mathrm{z}$ zaburzeniami ze spektrum autyzmu.

Do 2010 roku zgodnie z obowiązującym orzecznictwem osoby z autyzmem otrzymywały kod oznaczający niepełnosprawność np. z powodu wad neurologicznych lub choroby psychicznej. Zmiany w polskim orzecznictwie o niepełnosprawności wprowadzone w 2010 r. polegające na wprowadzeniu specjalnego kodu oznaczającego autyzm pozwoli na przybliżenie liczby urodzeń z zaburzeniami autystycznymi w Polsce. Wprowadzenie kodu pomoże urealnić

1 Rymsz A. Streszczenie Raportu 2013 - Autyzm Sytuacja dorosłych [w:] Autyzm w Polsce, Biuletyn 7, jesień 2014, s. 5-23.

2 Ibidem. S. 7 
szacunkowe liczby dotyczące urodzeń osób z autyzmem w Polsce, jednak nastąpi to dopiero za kilka lat.

Według danych Autism Europe 0,6 \% populacji Unii Europejskiej dotkniętych jest autyzmem, co stanowi około 5 milionów osób (szacunki z 2009 r.). Z kolei z szacunków dotyczących Stanów Zjednoczonych wynika, iż jedno na 166 urodzonych dzieci jest dotkniętych tym rodzajem niepełnosprawności. ${ }^{3}$ Analizując te dane, można stwierdzić, iż w ostatniej dekadzie nastąpił znaczny wzrost osób ze spectrum zaburzeń autyzmu. Wcześniej problem mało dostrzegany, dzisiaj staje się problemem ogólnospołecznym.

Podjęto już szereg działań, społecznych, samorządowych i innych, które starają rozwiązać zaistniały problem. Również w zakresie rozwiązań projektowania architektonicznego pojawiają się przykłady rozwiązań przestrzennych ułatwiających funkcjonowanie osób z zaburzeniami autyzmu.

Jednym z nieco dyskusyjnych, lecz niezbędnym, rozwiązaniem jest dołączanie do programu funkcjonalnego budynków bezpośrednio wykorzystywanych przez osoby z autyzmem, są tzW pokoje wyciszeń. Funkcją tego pomieszczenia jest zapewnienie możliwie bezpiecznego uspokojenia się osoby z zaburzeniami autyzmu, która dostała ataku agresji. W Polsce tego typu pomieszczenia najczęściej znajdują w szkołach specjalistycznych, ośrodkach szkolno wychowawczych. Bardzo często na potrzeby pokoi wyciszeń dostosowywane są pomieszczenia nie spełniające podstawowych wymogów dla celów jakim mają służyć. Bardzo często, niestety przypominają one izolatki w szpitalach psychiatrycznych z XIX wieku.

W wyniku badań ankietowych wykonanych przez autora niniejszej publikacji przeprowadzonych w okresie od 1.06.2015 do 20.12.2015, dotyczących oceny zachowań psychofizycznych osób niepełnosprawnych z zaburzeniami psychicznymi, stwierdzono iż niezwykle ważnym elementem, wspomagającym rehabilitację takich osób jest odpowiednio dobrana kolorystyka pomieszczeń oraz ich wyposażenie.

Badania w formie ankiety przeprowadzono na grupie 125 różnych osób zajmujących się osobami niepełnosprawnymi oraz z 75 osobami niepełnosprawnymi.

Wśród grupy osób zajmujących się osobami niepełnosprawnymi znaleźli się:

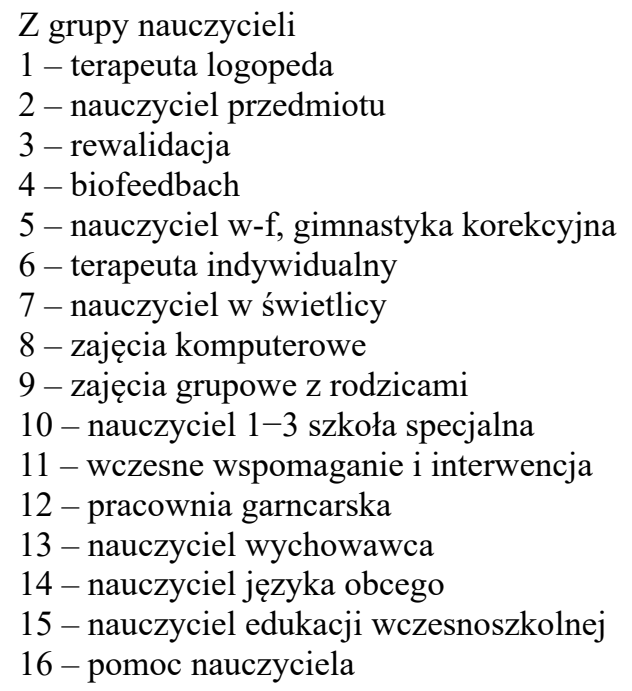

3 http://synapsis.org.pl/autyzm/ 
17 - psycholog

18 - terapeuta integracji sensorycznej

$\mathrm{Z}$ grupy opiekunów:

$1-$ Wychowawcy

2 - Opiekunowie prawni

4 - Rodzice

Ankieta została dostarczona do różnego rodzaju ośrodków zajmujących się osobami niepełnosprawnymi intelektualnie. Otrzymano wyniki z 85 ankiet wypełnionych na terenie Polski oraz z obszaru zachodniej Ukrainy.

W wyniku analizy uzyskanych wypełnionych ankiet stwierdzono iż:

1. Kolorystyka pomieszczeń pomieszczenia powinny być malowane w kolorach pastelowych, bez akcentów kolorystycznych. Jedynie w grupie osób niedowidzących powinny się pojawić mocno jaskrawe elementy w charakterystycznych punktach pomieszczenia umożliwiających lepszą orientację w pomieszczeniu.

2. Naświetlenie pomieszczeń - wszystkie grupy potwierdziły iż: pomieszczenia mieszkalne, pomieszczenia do nauki, pomieszczenia do rehabilitacji itd. powinny być lokalizowane na południowej ekspozycji budynku, z możliwie jak największą powierzchni ą okien. Jedynie pomieszczenia takie jak „doświadczania świata” powinny mieć ograniczony dostęp światła dziennego.

3. Wyposażenia pomieszczeń - wszystkie grupy potwierdziły iż wyposażenie tych pomieszczeń powinno być jak najbardziej minimalistyczne, wszystkie niezbędne elementy wyposażenia powinny posiadać swoje stałe miejsce, wszelkiego rodzaju pomoce dydaktyczne, pomoce naukowe itd. Jeśli są nie użytkowane powinny być chowane w szafach w stałych przeznaczonych dla nich miejscach.

4. Temperatura w pomieszczeniach - wszystkie grupy potwierdziły najbardziej optymalną temperaturę $\mathrm{w}$ pomieszczeniu $\mathrm{w}$ przedziale $21-22^{\circ} \mathrm{C}$.

Przykładowym rozwiązaniem „pokoju wyciszeń”, które odpowiada wynikom przeprowadzonej ankiety jest pomieszczenie wykonane w centrum handlowym Northland w Melbourne. 


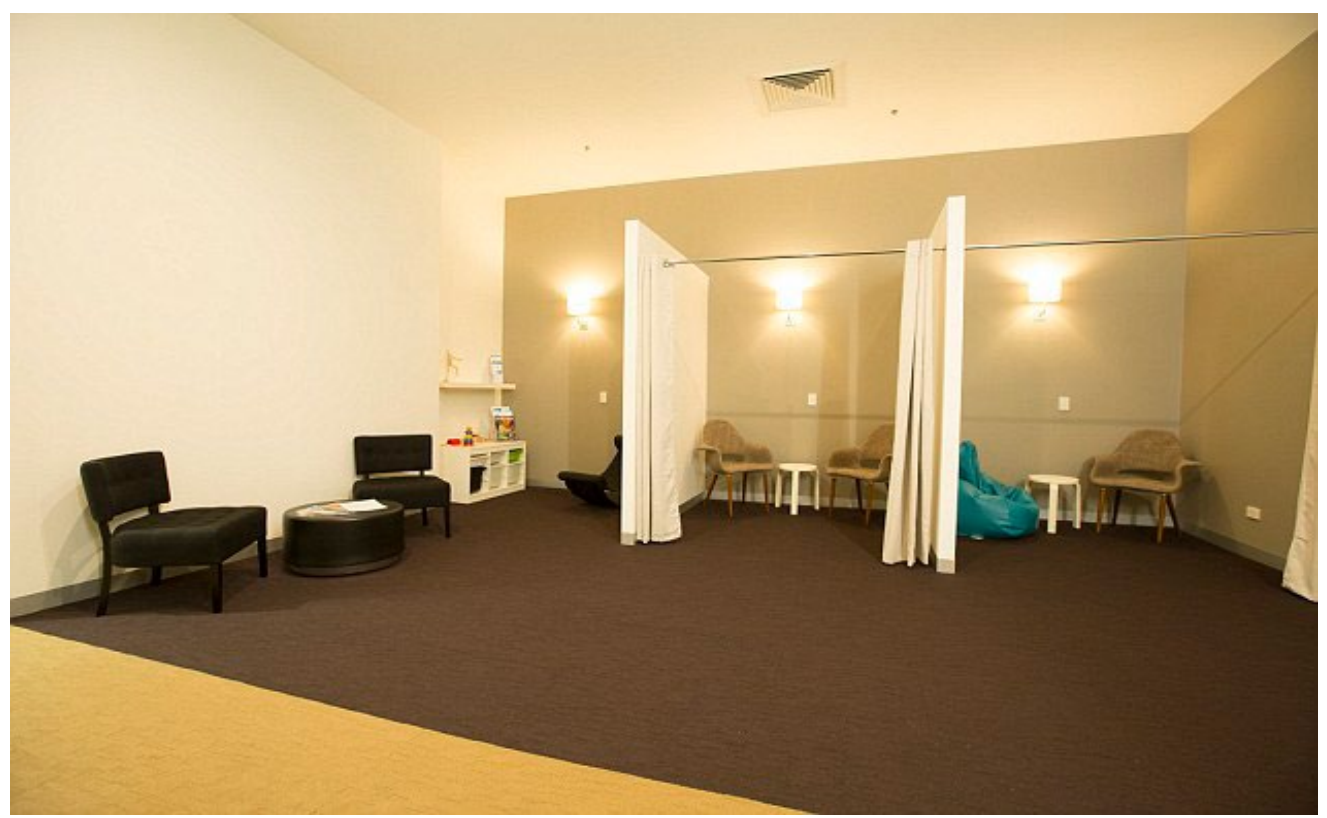

Ryc. 1. Wnętrze ,silent room” w centrum handlowym Northland w Melbourne Fig. 1. Interior of silent room in Shoppingcentre Northland in Melbourne

Układ funkcjonalny pomieszczenia umożliwia odpoczynek i powrót do równowagi psychicznej jednocześnie dwom osobom wraz z opiekunami. W programie użytkowym pomieszczenia zlokalizowano dwa aneksy do izolacji oraz niewielkie pomieszczenie socjalne.

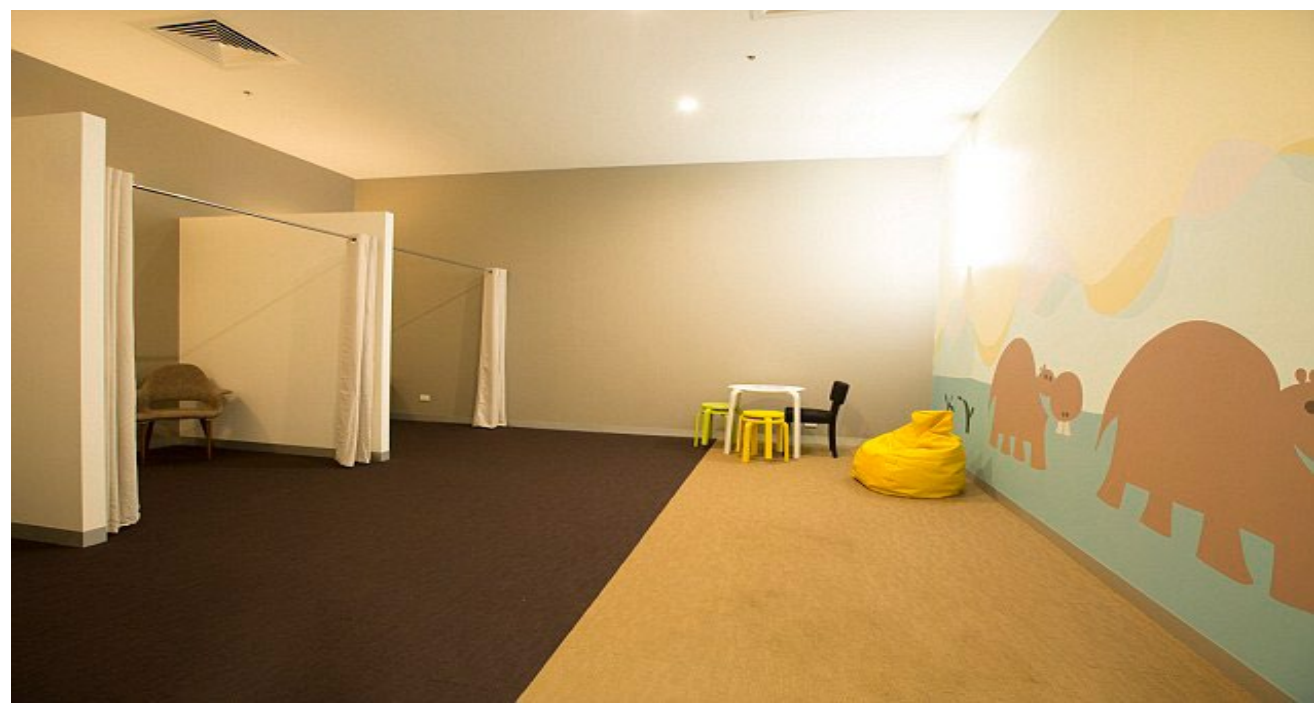

Ryc. 2. Wnętrze „silent room” w centrum handlowym Northland w Melbourne

Fig. 2. Interior of silent room in Shoppingcentre Northland in Melbourne

Zaproponowana kolorystyka - pastelowa bez kolorów jaskrawych również spełnia wymagania określone w trakcie analizy wyników ankiety. 
Elementy wyposażenia wnętrz są również dostosowane dla potrzeb osób ze spektrum autyzmu. Spełniają przede wszystkim warunki związane z bezpieczeństwem użytkowania, jak też formą i kolorystyką odpowiednią dla tych osób.

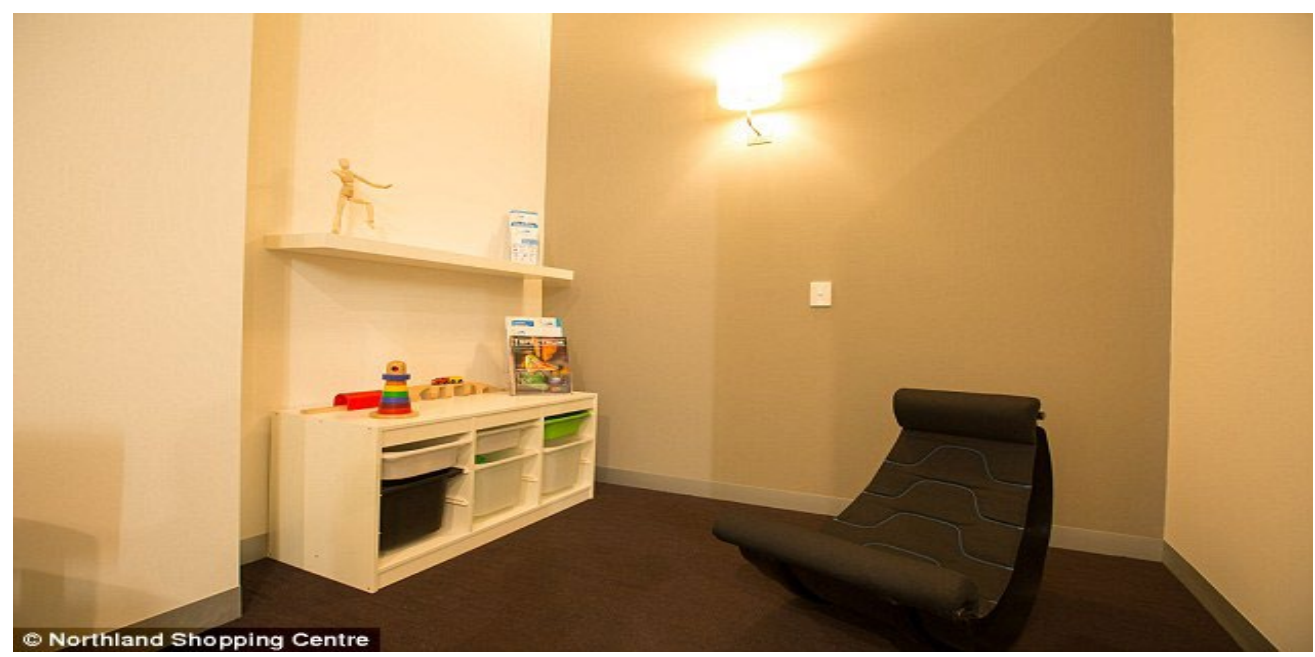

Ryc. 3. Wnętrze „silent room” w centrum handlowym Northland w Melbourne

Fig. 3. Interior of silent room in Shoppingcentre Northland in Melbourne

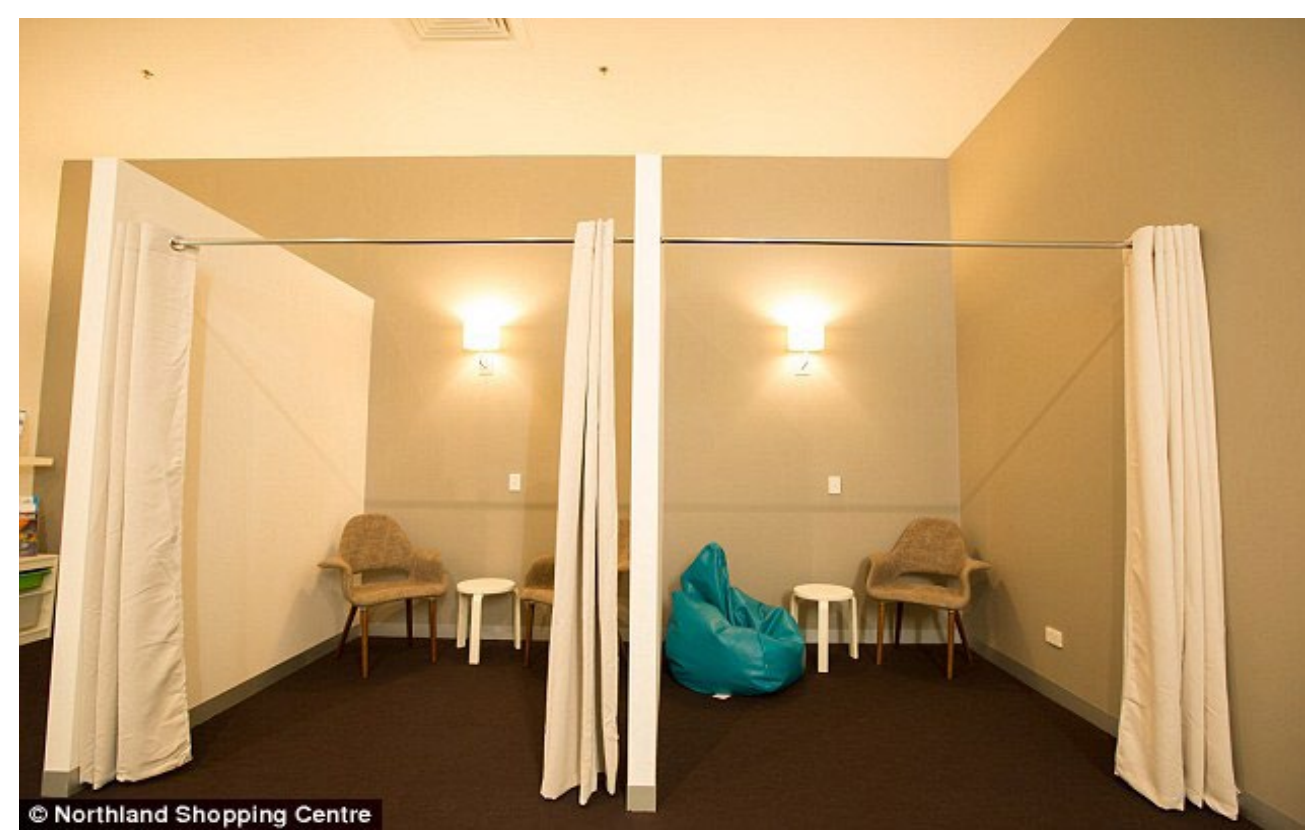

Ryc. 4. Wnętrze ,silent room” w centrum handlowym Northland w Melbourne

Fig. 4. Interior of silent room in Shoppingcentre Northland in Melbourne

Również bardzo wiele rozwiązań łączy w sobie kilka funkcji , poniżej przykłady wykorzystania pomieszczenia do rehabilitacji z możliwością uspokojenia pobudzonej osoby. 


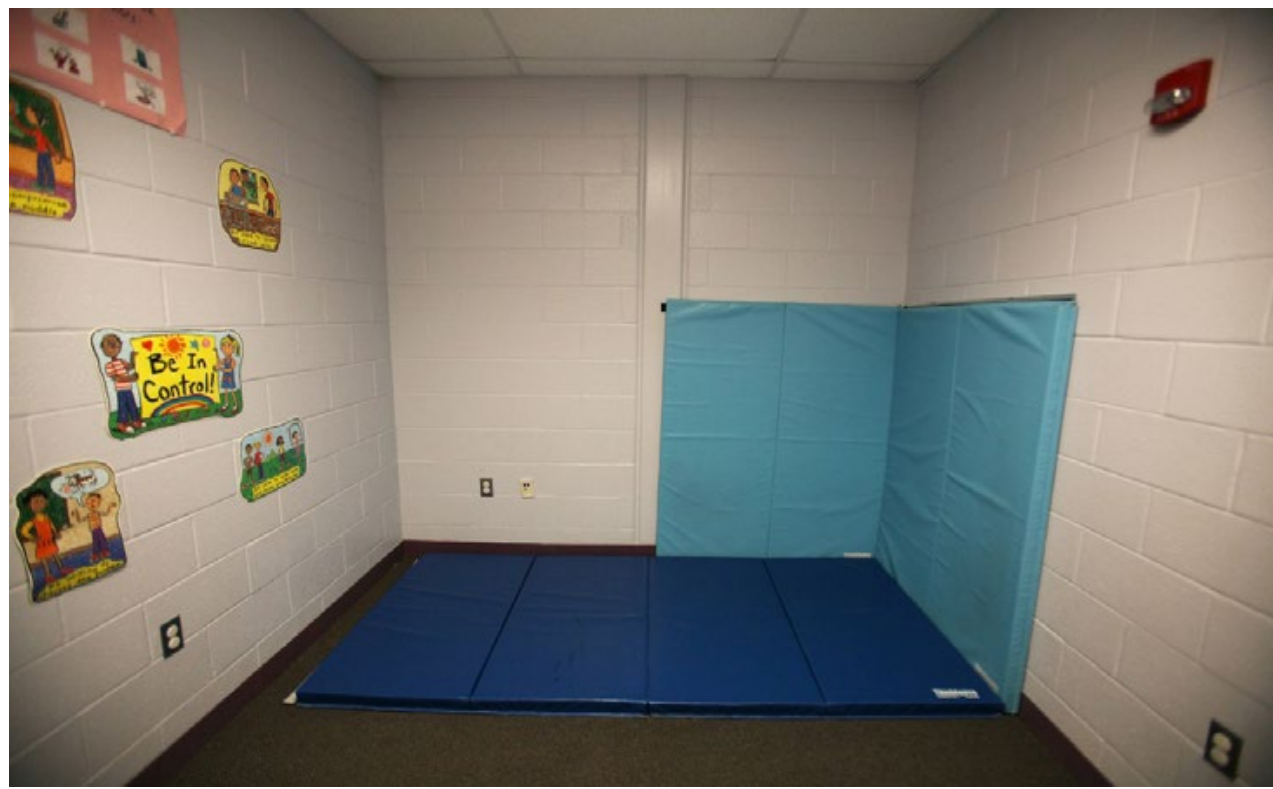

Ryc. 5. Przykład rozwiązania pokoju wyciszeń w szkole w Logan-Hocking, poprze umieszczenie materacy w narożniku pomieszczenia.

Fig. 5. A seclusion room used in a program for children with emotional disturbances in the Logan-Hocking school district has padding on the floor and in a corner

Przedstawione powyżej przykłady są jedynie przyczynkiem do dyskusji na temat projektowania pokoi wyciszeń.

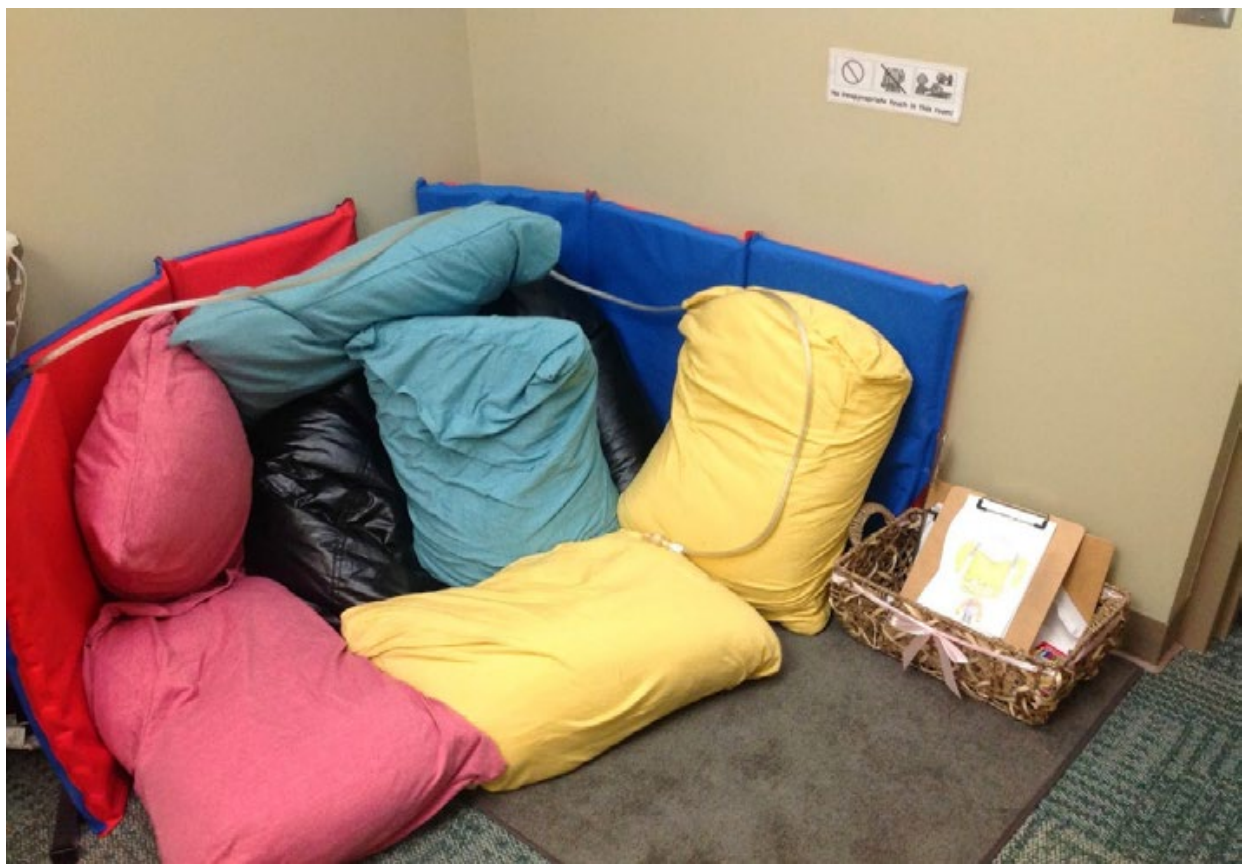

Ryc. 7. Przykład rozwiązania pokoju wyciszeń umieszczenie materacy w narożniku pomieszczenia. Fig. 7. A seclusion room used on the floor and in a corner 


\section{PIŚMIENNICTWO}

Rymsz A. Streszczenie Raportu 2013 - Autyzm Sytuacja dorosłych [w:] Autyzm w Polsce, Biuletyn 7, jesień 2014

Summary.

In the last decade it has significantly increased the number of people diagnosed with "autism spectrum disorders". Based on estimates, you can specify that in Poland is over. 30 thousand. people with autism, therefore the number of people affected by this problem is over 100 thousand. in Poland.

The growing demand for buildings and public spaces tailored to the needs of this group of people needs to systematize knowledge of architectural design takes into account the needs of people with autism spectrum disorders. The article presents the basic principles of the so-called shaping. "Quiet room"more often localized in public buildings.

\section{Keywords}

autism, environmental psychology, design, public buildings, quiet room. 